\title{
How does groundwater depletion contribute to unequal access to the resource among classes of farmers? evidences from case studies in the center of Tunisia
}

\begin{abstract}
Groundwater is considered as common pool resources. Managed under open access, this leads to overexploitation and generating of negative externalities that result in a decrease in water availability and increasing its pumping cost. Very often, the impact of these externalities is analyzed mainly in economic and environmental terms. At our knowledge, the studies concerned with social equity and equity access to resources through farmers' classes is limited in Tunisia. In the center of the country, where surface water is both scarce and random, groundwater is the only source of irrigation. Groundwater has transformed rural economies and therefore they can be considered as an example of success in achieving social welfare and economic growth policy objectives in these regions. However, such rapid growth has lead to serious overexploitation and piezometric level falls at the rate of 1 to 1.5 meter per year, threading thus the access to groundwater and the livelihood security for several tens thousands of small farmers. This study was undertaken in this context. Through using an economic optimization model, it seeks to analyze the distribution of the cost of externalities of overexploitation of aquifers and economic access to this resource through categories of farmers. The results show that unsustainable water results in significant economic losses to the farmer level, materialized by additional investments in irrigation, increased pumping costs and reduced income. However, the cost of these externalities is unevenly distributed. Indeed, it is at the level of small farmers that attends higher costs. As a result, this category is rapidly losing access to groundwater, further amplifying the existing inequalities in Tunisian rural society. Since regulatory instruments adopted so far (save areas, prohibition etc.) have shown their limitations, this work suggests the involvement of local users in the management of groundwater to ensure effective control of levies to preserve the groundwater and ensure the fairness of its operations. Significant agricultural policy reform is therefore necessary if we are to prevent further degradation of our groundwater. This study suggests the involvement of local users, with the assistance of CRDA, to ensure effective control on groundwater withdrawal. In addition to this policy, the Government should work to create another economic opportunities, in these regions, in order to alleviate pressure on groundwater resources exclusively caused by the horizontal and vertical extension of irrigated agriculture. Currently this sector constitutes the main source of revenue and jobs for the local population.
\end{abstract}

Keywords: policies, intensive irrigation, subsidized, groundwater depletion, inequalities
Volume 2 Issue 4 - 2018

Hacib El Amami

National Institute for Research in Rural Engineering, Water and Forests, Tunisia

Correspondence: Hacib El Amami, National Institute for Research in Rural Engineering, Water and Forests, Tunisia, Email hacib.amami@gmail.com

Received: June 19,2018 | Published: July 12, 2018

\section{Introduction}

In the central and southern parts of Tunisia, where surface water is both scarce and random, groundwater is the only source of irrigation. Indeed, favorable marketing opportunities for various crops and the easy and heavily subsidized availability of water lifting technology launched in the arid and semi-arid regions have led to a real intensive groundwater withdrawn, tapping reserves which could not be reached with older technologies. Current estimates show that 100,000 wells were installed and about 50percent of the agricultural area $(430,000 \mathrm{ha})$ is being irrigated by surface wells. This development is largely based on private investment in drilling wells, installing pumps and irrigation pipe, although the government has facilitated this development through provision of several incentives and concessions such as subsidized credit, diesel, fertilizers and extensive coverage of rural electrification. Groundwater has transformed rural economies through improved crop productivity and diversification, rising incomes of groundwater farmers as well as agricultural laborers' income. Such rapid growth, however, is not without serious environmental implications. In a virtually absence of effective regulation, the large scale adoption of surface wells have led to enormous extraction rates of groundwater, often exceeding natural recharge rates. This overexploitation has led to a rapid depletion of groundwater resources which has been apparent from dramatically lowering water tables and the drying up of many surface wells. Overall, up to a quarter of shallow aquifers have been estimated to be at risk due to groundwater depletion where the rate is $126 \% .{ }^{1,2}$

Economic theory attributes the overexploitation of aquifers to the property rights. Indeed, the property right of groundwater is not well defined (Sharif and Ashok, 2011). For centuries, groundwater rights are attached to land ownerships: the owner of surface land as also the owner of water under it. This unspecified stage of proprieties rights implies that the landowner can extract water as much as he desires without any kind of restrictions. Those who have the access to resources such as land and capital have higher incentive to extract as much water as possible and incentives to conserve groundwater voluntarily are absent, since water not pumped is available to 
competing users and will not necessarily be conserved for future periods. This is due because groundwater is classified as commonpool resource with the two characteristics: subtractability and low excludability (Ostrom, 1990). When it is exploited under open access regime, two externalities occur and prevent the efficient exploitation of the resource: stock externality and cost externality. The stock externality arises when extraction rate exceeds natural recharge rate and its impact will be most acute in fragile areas when the aquifer does not receive enough natural recharges, like the center and the south of Tunisia. Pumping cost externalities arise because the cost of pumping groundwater depends on the groundwater stock. As water table drops with every unit of water extracted the cost of pumping the next unit increases as a consequence of increasing lift and additional invest cost to capture deeper water.

However, the impact of these externalities appears to be differential and closely follows the structure of land ownership in the sense that farmers of small holdings would be the most vulnerable to overexploitation. The magnitude of the problem is poorly documented in Tunisia, in particularly in arid and semi-arid areas where surface water is scarce and groundwater is the main source of irrigation. In these areas, farmers responded to declining water tables by deepening the well, drilling a new well or, at least, installing powerful pumps (Feuillette, 2001). With the increased drop on groundwater level, this results in a spiraling cycle of well deepening or re-drilling and the purchase of new pump sets. This capital intensity of groundwater extraction has serious social implications for the poorest and small farmers, who can no longer afford such action and risk exclusion from access to groundwater for their irrigation. Declining water table coupled with deepening of existing wells and digging of new wells aggravates overexploitation of groundwater and threatens the livelihood security of small farmers and makes easy to exclude rival users, especially in the severely affected regions. Therefore, groundwater resource becomes used largely by a few numbers of farmers. The consequences for rural poverty and economic growth are potentially serious, given that 90 percent of farmers are small and depend largely on agriculture for their livelihoods. Many cases studies conducted in several regions of the world highlighted the serious equity implications of groundwater exploitation with falling water levels particularly in the water-starved regions. ${ }^{3,4}$

The present study was carried out in this context. It seeks to analyze economic access to groundwater and the distribution of externalities resulting directly from groundwater depletion among different categories of farmers using surface well in the central part of Tunisia. It has looked into the cost of groundwater extraction, impact of groundwater over-draft on farm income, water-use efficiency and technical efficiency in crop production, and costs of groundwater over-draft. The consequences of groundwater depletion and its linkage with rural income and inequity across different types of farmers were also analyzed. The paper is structured as follows. The section 2 gives description of the study area and a full description of the mathematical programming model developed within this study. Section 3 presents and discusses the main results. The concluding section 4 proposes measures to prevent over-exploitation of groundwater resources in the context of the study area.

\section{Methodology}

\section{Study area}

The geographic setting for this analysis is the region of KharroubaEl Maloussy located in Sidi-Bouzid in central parts of Tunisia (Figure
1). Strongly governed by the arid climate, the average annual rainfall calculated during the period (1936-2012) was approximately $180 \mathrm{~mm}$ and characterized by significant annual fluctuations with a coefficient of variation ranging from $25 \%$ to $80 \%$. About $56 \%$ of precipitation occurs between September and April. The average annual evaporation is $1470 \mathrm{~mm}$ per year and the ratio of evaporation to rainfall for the area is 7.5. Therefore, agriculture is primarily based on intensive irrigation, since rainfall hardly meets 30 to 35 per cent of the water requirements even for winter crops. Due to the aridity of the climate, the area has little surface water and groundwater is the only source of water irrigation. The aridity of the climate has led to an increasingly widespread use of irrigation. This rapid development has been facilitated by the general orientation of the State in the field of agricultural policy, which consists in increasing the mobilization of water and the extension of irrigated areas. According to the landholding and grown crops, the farming systems were grouped as small farms, medium farms and larger farms. Small farmers, whose land holdings are below 5 hectares, constitute almost $80 \%$ of all farmers. They allocate larger proportion of their cultivated land to high value crops like vegetables. These crops are short duration crops which helped increasing cropping intensity on smaller size of farms. They seem to have comparative advantage in growing vegetables than fruits because of quick returns in the former. Sericulture is also a component of farming systems for many small farmers that are oriented to activities with low investment and shorter gestation period. Sericulture is labor-intensive activity and is well suited to small farms with surplus labor, especially female labor. Medium farmers owning between 7 and 10ha of irrigated land, cultivate vegetables in association with fruit particularly olive and almond trees. Unlike small farmers, vegetables and fruits trees are cultivated on separate parcels. However, in addition to these two prevalent categories, a third category (large farmers) was implemented at the beginning of this millennium and cultivated an irrigated area often exceeds 15 ha. Their farming system rely exclusively on fruits trees, planted at high density with 1000-2000 trees per hectare and conducted under hyper intensive irrigation regime. The fruits trees include: olive, almond and peaches.

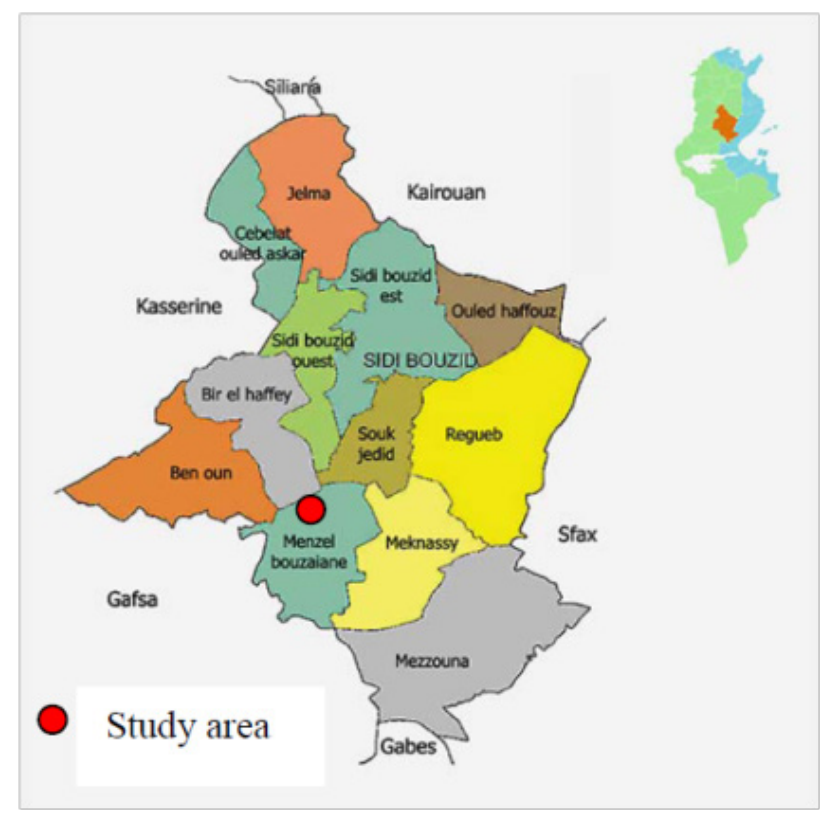

Figure I Location of study area. 
In order to take into account the differential impact of groundwater depletion, the study was conducted on a survey of 47 farmers covering the different categories of farmers. A structured research questionnaire was developed and administered to the selected sample in each category to obtain information on the evolution of irrigation via groundwater (history and current situation use). The first part of the questionnaire deals with the investment in wells, water depth, well yields, grown crops, water irrigation technologies and energy used to pump water etc. Farmers were also asked about the number of deepening the existing wells or digging of new wells as well as the associated cost and the current crops grown. The respondents were requested to suggest some possible solutions to save groundwater and to give their view about some new instruments. The second part of the questionnaire extracts detailed information on cropping patterns, area under irrigated crops, the level of inputs used for each crop at different stages of production and their costs, such as: seeds, fertilizers, labor, mechanization, pesticides, pumped water and cost. The collected data was used in a first step to generate enterprise budget: production cost, gross margin and economic water rent for each growing crop and each representative farm. In a second step, it was used as input for economic model optimization, developed for a representative farm for each category to analyze the impact of groundwater depletion on farmers' income.

\section{Conceptual framework}

The impact of groundwater depletion on social equity and economic income of different classes of farmers was simulated in a mathematical programming model. Mathematical programming model seeks to determine the optimum allocation of constrained resources among competing activities under deterministic and risky conditions so as to maximize net return from agricultural production (Hazell and Norton, 1986). This method was chosen over other possible methods because of its practical and theoretical appeal and because of the ability to examine optimal water allocation to alternatives crops under increasing pumping costs. The model integrates information on investment cost of drilling and deepening wells, energy prices and pumping depth with current agricultural practices, including irrigated cropping alternatives, irrigation technologies choices and multiples irrigation levels (deficit irrigation) to determine the potential impact of groundwater depletion on pumping cost, water strategies allocation and farmer's income. A non- linear programming model representing a single growing season was developed for a representative farm for each farm types. The model will choose the optimal cropping pattern, among different alternatives, which satisfies the existing land and water availability constraints, as well as agronomic and economic conditions of crop production for each category of farms. The objective function was defined as:

$\operatorname{Max} Z=\sum_{j=1}^{j=n} P_{j} \times R_{j t} \times Y_{j t}-\sum_{j=1}^{j=n} C_{p w} \times W_{j} \times Y_{j}-\sum_{i=1}^{i=n} \sum_{j=1}^{j=n} \beta_{i} \times D_{i j} \times Y_{j}-A C_{d w}-A C_{p s a}$

Where:

$\mathrm{Z}$ is the farmer income, $\mathrm{P}_{\mathrm{j}}$ is the price per kg or ton of crop " $\mathrm{j}$ ”, $\mathrm{R}$ is the average yield per ha of crop “ $\mathrm{j}$ ”, $Y_{j}$ is level of crop “ $\mathrm{j}$ ”, expressed in ha, $\mathrm{W}_{\mathrm{j}}$ is the pumping cost per cubic meter, $\mathrm{C}_{\mathrm{wj}}$ is the pumped water used by crop " $\mathrm{j}$ ", $\mathrm{D}_{\mathrm{ij}}$ is the variable cost of input (resource) " $\mathrm{k}$ ", other than water", such fertilizer, seeds etc, used crop " $\mathrm{j}$ ", $\mathrm{AC}_{\mathrm{dw}}$ amortized cost of deepening the well, $\mathrm{AC}_{\mathrm{psa}}$ amortized cost of pumps and accessories.
The objective function (equation 1) was maximized subject to several constraints including limits on the availability of land, water and limits on other production resources (e.g., labor, capital etc.):

$$
\sum_{j=1}^{j=n} a_{i j} Y_{j} \leq B_{i}
$$

$\mathrm{a}_{\mathrm{ij}}$ matrix of technical coefficients, it represents the amount of resource (i) required to produce one unit of $Y_{j}$ activity, $B_{i}$ total availability of resource "i". Equation (3) defines the cost of pumping water over a given period $\left(\mathrm{C}_{\mathrm{t}}\right)$, as expressed by Rogers \& Allam ${ }^{5}$

$$
C t=\mu \times\left(h_{0}+\Delta h t\right) \times \delta
$$

The pumping cost $\left(\mathrm{C}_{\mathrm{t}}\right)$ is assumed to be a function of fuel price $(\mu)$ and the well depth $\left(\mathrm{h}_{0}+\Delta \mathrm{h}_{\mathrm{t}}\right)$, measured in meters, as being the distance from the land surface to the static level of the aquifer. The coefficient $\mu$ represents the price of the unit of energy used, $h_{0}$ the initial depth of the well in meters, taking 2000 as the base year, and $\delta$ the energy required to lift one unit of water $\left(\mathrm{m}^{3}\right)$ one unit of distance $(\mathrm{m})$. This coefficient $(\delta)$ is defined by: $\delta=(\gamma \times \rho \times g) / 1000$; in which $\gamma$ is the efficiency of the pump; taken equal to $75 \%, \rho$ is the density of water $\left(1000 \mathrm{~kg} / \mathrm{m}^{3}\right)$ and $\mathrm{g}$ is the acceleration of gravity $\left(9.8 \mathrm{~m} / \mathrm{s}^{-2}\right)$. The coefficient $\Delta \mathrm{h}$ which represents the drawdown of the water table during the year " $\mathrm{t}$ " is obtained from the service of Regional Department of Agriculture (CRDA). Using equations (3), pumping costs are adjusted each period to reflect the higher costs associated with increased lift and increased energy prices. Water supply was assumed not to be limiting except as the cost of water is affected by both well depth and energy prices.

The investment in deepening the well was amortized as follows (equation 4):

$$
A C_{d w}=\frac{\left(D \cos t \times(1+i)^{r d} \times i\right)}{(1+i)^{r d}-1}
$$

Where, $D_{\text {Cost }}$ is the investment on deepening the well in current prices, $i=$ interest rate and $r d$ is the average life of a well deepening operation; in study area it ranges generally between two and four years.

Similarly, the investment made on pump sets and accessories was amortized as follows:

$$
A C_{p s a}=\frac{\left(P \operatorname{cost} \times(1+i)^{d p} \times i\right)}{(1+i)^{d p}-1}
$$

Where $P_{\text {cost }}$ is the investment on pumps set and accessories and $d p$ the average life. The working life of pump set and accessories is assumed to be ten years.

Only the investment costs made in deepening well and purchasing new pumps set were taken into consideration. Those relative to initial investments have been not taken into account in this study.

The amortized investment cost (AIC) in irrigation is then the sum of the amortized investment in deepening the well amortized investment and the amortized investment made on pump sets and accessories needed after deepening the well (equation 6):

$$
A I C=A C_{d w}+A C_{p s a}
$$

Amortized cost per cubic meter of groundwater extracted is obtained by dividing amortized cost of irrigation well by total groundwater used on farm. 


\section{Results and discussion}

\section{Trend of groundwater depletion}

The existence of large quantities of intact underground water suitable for irrigation and the profitability of irrigated production have resulted in rapid irrigation development over the past three decades. This development is largely based on private investment in drilling wells, installing pumps and irrigation pipe, although the government has facilitated this development through provision of several incentives and concessions such as subsidized credit, diesel, fertilizers and extensive coverage of rural electrification. This played a key role in pushing farmers to grow vegetables and intensive plant tree at enormous detriment to water resource sustainability in the region. Therefore, the number of wells was more than quintupled from 131 wells in 1987 to nearly 700 in the early 2000s. Today the number of wells reaches 850 and the area has the highest concentration of wells where the density can reach up to 20 wells $/ \mathrm{km}^{2}$ (Daoud and Trautmann, 2001). The considerable increase in the number of wells has led to a situation of overexploitation of water table. Out of an annual renewable potential estimated at 4 millionm ${ }^{3}$, nearly 5.5 millionm $^{3}$ are currently used, giving a rate of over-exploitation of $137 \%$. The aquifer piezometric level has gone down considerably and continuously, as shown by Figure 2. Farmers, who used to pump from 21 to $23 \mathrm{~m}$ below the surface at early $1990 \mathrm{~s}$, are drilling to depths exceeding $31 \mathrm{~m}$ in 2008 and to depth ranging between 34 and $36 \mathrm{~m}$ today. On average, the groundwater table is falling at approximately a rate of 1 meter per year, as opposed to just $25-30 \mathrm{~cm}$ per year during the mid-1980s. According to farmers, it reaches in some places 1.5 to $1.8 \mathrm{~m}$ per year. Due to decline in water table depth, the totality of farmers reported that they have to deep their wells regularly, once every 2-3 years, increasing thus the energy requirement to left one meter cubic which has an additional impact on pumping cost. This operation requires considerable financial capital and incurs additional charges for the acquisition of energy and installing more powerful pumps.

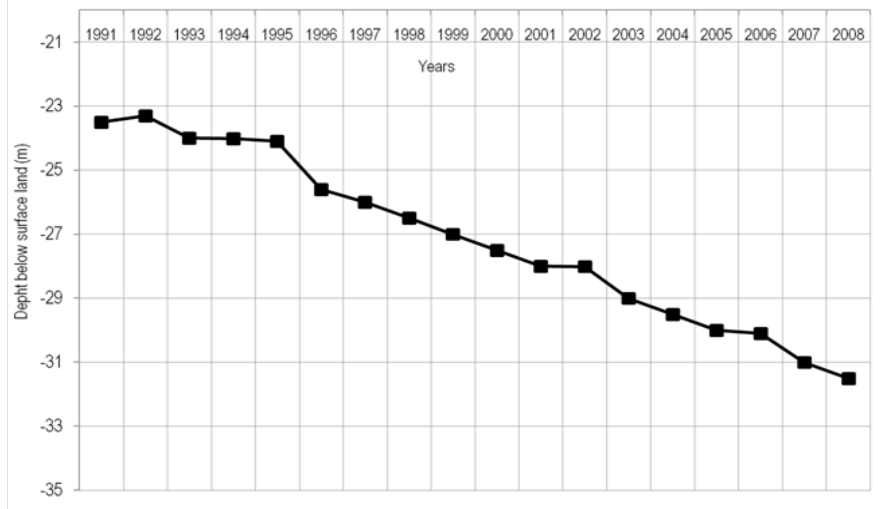

Figure 2 Evolution of piezometric level from 199I to 2008 in the study area. ${ }^{8}$

\section{Groundwater depletion consequence}

\section{Increasing pumping cost}

The pumping cost is generally assumed to be a function of energy price and pump lift. This means that as the groundwater stock is depleted, extraction costs rise, even if energy prices remain constant. The model results showed that, combined with the increase of energy prices (diesel prices), the groundwater depletion have led to a spectacular increase of pumping cost by $385 \%$ over the past 15 years, shifting thus from $0.065 \mathrm{TND} / \mathrm{m}^{3}$ in 2000 to $0.315 \mathrm{TND} / \mathrm{m}^{3}$ in 2014 (Figure 3). This cost includes only the price of energy used that is the same for all categories of farmers. The increase of energy prices over this period explain 65 percent of the pumping cost increase, while the remaining 35 percent is explained by the increasing of pumping depth. Even, if we keep energy prices constant, Figure 1 showed that, under the effect of groundwater depletion, the pumping cost have almost doubled during the past 15 years, shifting from 0.065 TND per cubic meter in 2000 to 0.13 TND per cubic meter in 2014. Indeed, due to the decline in water table depth, the farmers have to deepen their wells regularly increasing thus the energy requirement to left one meter cubic which has an additional impact on pumping cost. Such cost would certainly affect the economic performance of irrigated crops and consequently farmers' incomes, particularly in the study area where the cost of irrigation represents the major component of the variable cost. It can reach $50 \%$ of the variable cost for summer crops like tomatoes, pepper and water melon.

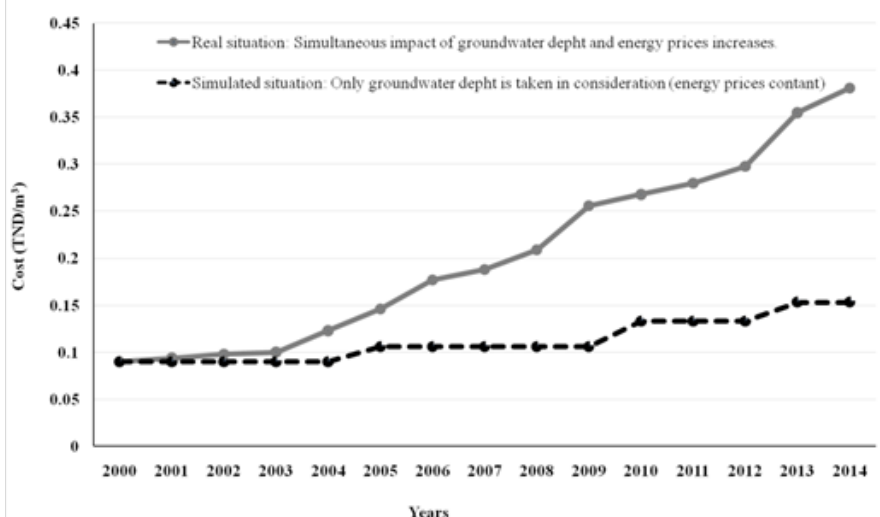

Figure 3 Evolution of groundwater pumping cost between 2000 and 2014 .

\section{Access to groundwater}

Following Reddy ${ }^{6}$ two indicators, namely physical and economic access, were used in this study to discuss the equity of access to groundwater through the classes of farmers. Physical access to resource is the volume of groundwater used by farmers, measured in terms of cubic meter per year and in terms of cubic meter per unit of cultivated area. ${ }^{7}$ Economic access is measured in terms of the cost per unit volume of water used. These two indicators (physical and economic) allow us to assess the social equity of access to groundwater. Social equity implies fair access to resources and to equal redistribution of the wealth produced by the economy through the different individuals or groups of society. In general it implies that the services and benefits generated from availability/allocation of given resources must be distributed in an equal manner or in a way that the most disadvantaged people receive more benefits (Cai, 2008). In this study, social equity refers to the analysis of equality of chances among farmers' groups to access to groundwater resource. It is a vital aspect in the study of economics of groundwater as it emphasizes those classes of farmers who might benefit from this resource in the context of continuous fall of groundwater depth.? 


\section{Physical access to groundwater}

As it is shown in Table 1, physical access to groundwater resource is significantly better for large land owners compared to small holders. Indeed, the volume of water pumped by the large farm is almost 5 times higher than that pumped by the small farm, suggesting at priori that the volume of annual pumped water increases as the farm size increases. (G-D-Inequity12). Although the size of land ownership is a necessary prerequisite for access to groundwater in the study area, it does not appear to be the only determinant factor for acceding to this resource. The availability of financial capital plays an important role in using groundwater. ${ }^{8,9}$ This is clear from Table 1 . Thus, even if we exclude the land retention factor and analyze physical access to groundwater on the basis of one hectare for each class, we observed that the groundwater used per hectare by the small holding size is the lowest. Therefore, small farmers are doubly affected by groundwater depletion: on the one hand there is an increase of physical shortage c. of water and on the other hand there is also a lack of capital needed for invest in capture more deeper water. If we aggregate the annual pumped volume at the level of the study area, we observe that the share of small farmers accounts for only $11 \%$ of all water withdrawals, while they represent $70 \%$ of farmers in the region. Large farmers consume $58 \%$ of the volume pumped, while they represent only $8 \%$ of farmers.

\section{Economic access to groundwater}

Economic access was analyzed through two indicators:

a. Increasing pumping cost and

b. Additional investment cost in irrigation, including amortized cost of deepening the well and purchasing powerful pump with accessories. As shown by Table 2 .

Table I Physical access to groundwater through the categories of farms

\begin{tabular}{llll}
\hline Components & Small farms & Medium farm & Large farm \\
\hline Land holding size (ha) & 3 & 6 & 10 \\
\hline Cultivated crops & $\begin{array}{l}\text { Bean, peas, peppers and onions, } \\
\text { planted in separately parcels or within } \\
\text { olive trees. }\end{array}$ & $\begin{array}{l}\text {-Peas, Olive and } \\
\text { Almond trees. }\end{array}$ & $\begin{array}{l}\text { Olive, almonds and } \\
\text { peaches trees. }\end{array}$ \\
\hline $\begin{array}{l}\text { Water pumped per } \\
\text { year }\left(\mathrm{m}^{3}\right)\end{array}$ & 13500 & 34800 & 68000 \\
$\begin{array}{l}\text { Water used per ha/ } \\
\text { year }\left(\mathrm{m}^{3}\right)\end{array}$ & 4500 & 5800 & 6800 \\
\hline
\end{tabular}

Table 2 Economic access to groundwater by farmer's categories

\begin{tabular}{llll}
\hline Components & Small farms & Medium farms & Large farms \\
\hline Pumped water $\left(\mathrm{m}^{3} /\right.$ year) & 13370 & 34800 & 68000 \\
Amortized investment in irrigation $\left(\mathrm{TND} / \mathrm{m}^{3}\right)$ & 0.056 & 0.011 & 0.006 \\
$\begin{array}{l}\text { Total cost of pumping water (amortized investment }+ \\
\text { energy cost) }\end{array}$ & 0.162 & 0.117 & 0.112 \\
\hline
\end{tabular}

The investment cost in irrigation increased with the decrease in the holding size. It was the highest for small farmers with 374TND/ ha, followed by medium with $107 \mathrm{TND} / \mathrm{ha}$. For large farms this cost is only $50 \mathrm{TND} / \mathrm{ha}$, which is 7.5 times lower than that observed for small farmers. This is because small farmers have to bear the same amount of investment on deepening the existent well, as that of large farmers, but large farmers have the possibility to irrigate more area given their large size of holding and thus enjoy the benefits of scale economies. ${ }^{10}$

The cost per cubic meter of pumped water, including both the cost of energy and amortized cost of investment, was also highest for small farmers with $0.162 \mathrm{TND}$, followed by medium farmers with 0.117 TND. This cost decreases as the area increases, so that economic access increases with the size of the farm and vice versa. This inequality in cost of groundwater irrigation across different categories of the farmers was mainly due to the lower irrigable area with higher investment. As indicated, small farmers have to incur the same amount of investment on deepening the existent well, as that of a large farmer but a large farmer can irrigate more area given his large size of holding and thus enjoy the fruits of scale economies. The cost per cubic meter of water extracted, including both the cost of energy and amortized cost of investment in irrigation, was also highest for small farmers with 0.162 TND, followed by medium farmers with $0.117 \mathrm{TND}$ and large farmers with $0.112 \mathrm{TND}$. Thus, the pumping cost per cubic meter increases, as the irrigated area decreases, implying that economic access to groundwater becomes increasingly in favor of large farmers. Given that groundwater is considered as common pool resources and exploited under open access regime, the increase of economic access indicators (investment cost, water pumping cost) will likely forces small farmers to abandon their legitimate share in these common resources. They may lose totally the access to groundwater and instead improving equity, groundwater will further exacerbating inequalities already prevalent in Tunisian rural society.

\section{Groundwater depletion and income}

Besides direct cost indicated precedent, groundwater degradation would incur also farmer's indirect costs. Indirect costs are those costs that are incurred due to likely decline in the area under irrigation and the changes in cropping pattern, which could have a dramatic effect 
on farmers' incomes. To quantify these costs and their differential impact through classes of farmers, we have simulated an additional fall of the aquifer by 5meter, increasing thus the groundwater depth from 30 meters currently to 35 meters in the next $4-5$ years. For small farmers, model results showed that, although the irrigated surface remained unchanged relative to initial situation, the cropping pattern has shifted away from the more remunerative water intensive crops, like tomatoes, peppers and water melon to other less remunerative dry crops, like most winter crops: peas, bean, winter wheat and fodder crops. For large farms, the cultivated area under irrigation remained the same and the cropping pattern was composed by olive, peaches and almonds trees as in the initial situation presented in Table 3. However olive trees were proposed under deficit irrigation regime. Increasing groundwater depth by 5 meter leads therefore to a fall in the revenue of small farmers by $23 \%$ and an increasing pumping cost by $13 \%$ relative to initial situation as shown by Table 3 . Whereas the same increasing depth will decreases profit only by $6 \%$ for large farm group and increases pumping cost by $14 \%$.

Table 3 Differential impact of additional groundwater depth $(5 \mathrm{~m})$ on pumping cost and income throughout farmers' categories

\begin{tabular}{lllllll}
\hline & \multicolumn{2}{l}{ Small farmers } & \multicolumn{2}{l}{ Medium farmers } & \multicolumn{2}{l}{ Large farmers } \\
\cline { 2 - 6 } & Pumping cost & Simulated situation & Initial situation & Simulated situation & Initial situation & Simulated situation \\
\hline Percentage & $+17.5 \%$ & $-13 \%$ & $+16 \%$ & $-7 \%$ & $+14 \%$ & $-6 \%$ \\
\hline
\end{tabular}

Based on these results we can say that the burden of groundwater overexploitation in terms of falling income and increased investment cost as well as pumping cost, were unequally distributed among categories of farmers. In the study area, large farmers are much less affected compared to medium and small farmers, particularly. Therefore, it is expected that these farmers continue to enjoying their share on groundwater resources as they are able to remedying the declining groundwater table by deepening the wells with low cost or by drilling new borehole. But marginal and small farmers, owning less than 2 and 3 ha respectively, would be in quite vulnerable position. In order to be able to remain in the race of competitiveness of groundwater extraction and therefore kept their share in this precious resource, they have to keep on investing in well deepening activities. Drilling a borehole is clearly appears beyond the financial capacities of these categories of farmers. One innovative alternative consists to drill boreholes by a few neighboring farmers, so that all investment cost will be shared by the co-owners. Irrigation scheduling will be done according to specified rules defined by the co-owners. Besides, small farmers should take initiatives in efficient use of groundwater by adopting efficient irrigation technologies; better irrigation management at plot level and any other on-farm practices witch improve water use efficiency. They should also introduce flexibility in cropping pattern by shifting away from high-added value crops, but requiring much water like vegetables (tomatoes, peppers and water melon) to less-remunerative crop, but requiring less water, like winter crops (peas, bean, winter wheat and fodder). The introducing of olive trees is a promise activity production that should be encouraged for to be adopted by small farmers in condition of groundwater depletion. This crop has experienced a spectacular increase of its market prices during the last few years, making it one of the most profitable crops. In addition olive tree is well known as one of most drought tolerant crops in the region. ${ }^{11,12}$

\section{Conclusion}

This study showed that unsustainable water results in significant economic losses to the farmer level, materialized by additional investments in irrigation, increased pumping costs and reduced income. However, the cost of these externalities is unevenly distributed. The study has shown that there is a large difference between large and small farms in their access to groundwater resource in terms of cost. Indeed, it is at the level of small farmers that attends higher costs. As a result, this category is rapidly losing access to groundwater, further amplifying the existing inequalities in Tunisian rural society. Since regulatory instruments adopted so far (save areas, prohibition etc.) have shown their limitations, this work suggests the involvement of local users in the management of groundwater to ensure effective control of levies to preserve the groundwater and ensure the fairness of its operations. Significant agricultural policy reform is therefore necessary if we are to prevent further degradation of our groundwater. This study suggests the involvement of local users, with the assistance of CRDA, to ensure effective control on groundwater withdrawal. In addition to this policy, the Government should work to create another economic opportunities, in these regions, in order to alleviate pressure on groundwater resources exclusively caused by the horizontal and vertical extension of irrigated agriculture. Currently this sector constitutes the main source of revenue and jobs for the local population.

\section{Acknowledgements}

None.

\section{Conflict of interest}

The author declares there is no conflict of interest.

\section{References}

1. Ben Guessim A. Water resources in Tunisia (in Arabic). National Day on Water in Development. UTAP, Tunis; 2014.

2. Ben Guesssim A. For a new vision of the underground water management. Workshop on: Valorization of Scientific Research Achievements in Water Sector. Gammart, Tunisia; 2015.

3. Shah T. Groundwater Markets and Irrigation Development: Political Economy and Practical Policy. New Delhi: Oxford University Press. 1995;71(2):261-264.

4. Moench MH. Chasing the water table. Equity and sustainability in groundwater management. Economic \& Political Weekly. 1992;27(5152):A171-A177.

5. Rogers DH, Alam M. Comparing irrigation energy costs. Irrigation Management Series MF-2360. 1999;1-4.

6. Reddy VR. Costs of resource depletion externalities: a study of groundwater overexploitation in Andhra Pradesh, India. Environment and Development Economics. 2005;10(4):533-556.

7. Diwakara H, Chandrakanth MG. Beating negative externality through groundwater recharge in India: a resource economic analysis. Environment and Development Economics. 2007;12(2):271-296. 
8. DGRE. Piezometric Yearbook of Tunisia. Ministry of Agriculture and Hydraulic Resources. 2014;329.

9. Kumar MD. Impact of electricity prices and volumetric water allocation on energy and groundwater management: Analysis from western India. Energy Policy. 2005;33(1):39-51.

10. Tushar S. Taming the anarchy: Groundwater Governance in South Asia Resources for the Future, Washington, DC. 2009. p. 305.
11. Anantha KH. Downward Dividends of Groundwater Irrigation in Hard Rock Areas of Southern Peninsular India. Working Paper 225, The Institute for Social and Economic Change, Bangalore. 2012;1-22.

12. Dubash NK. Tube Well Capitalism: and Groundwater Development an Agrarian Change in Gujarat. New Delhi: Oxford University Press. 2012. 